\title{
Tier 2 CAMHS and its interface with primary care
}

\author{
Peter Appleton
}

During the past decade, increasing attention has been paid to the primary care level of service for children and adolescents with mental health problems. In particular, a number of national reports have advised service commissioners and providers to increase the amount of specialist child and adolescent mental health services (CAMHS) support to primary care colleagues (Department of Health/Department for Education/ Social Services Inspectorate, 1995; National Health Service (NHS) /Health Advisory Service (HAS), 1995; Audit Commission, 1999).

\section{Primary care}

Primary care health services have six key characteristics (Starfield, 1992), which are outlined in Box 1.

In the UK, NHS primary care services are designed to provide preventive, diagnostic, treatment and rehabilitation services, either directly or through access to comprehensive specialist services. NHS general practices have both a public health function and a medical consultation function, the latter triggered by individual citizens seeking help.

\section{NHS primary care CAMHS}

Children experiencing psychiatric disorder tend to go to their general practitioner (GP) frequently. They are likely to present with physical symptoms, and the detection rate of psychiatric disorder by the GP is low, unless symptoms are severe. Detailed discussion of these services is provided in a recent paper in this journal (Kramer \& Garralda, 2000) and elsewhere (Bowman \& Garralda, 1993; Garralda, 1994).

\section{Schools as primary care CAMHS}

Children's mental health problems also present in school settings (Rutter, 1989). Multi-disciplinary 'child guidance' services and special educational services for these children have existed for many years (Department of Education and Science, 1978). But to what extent do schools function as primary care CAMHS (see Box 1)? By virtue of being present in school, children have first contact access to general and special educational help for school-based child and adolescent mental health problems. Longitudinal care is provided by the child's teacher and head teacher during the school years. Schools provide gate-keeping access to special educational help, NHS-based multi-disciplinary Tier 3 and 4 services, and social care provision. Head teachers and special educational needs coordinators (SENCOs) have a statutory responsibility to coordinate help for individual children's school-based special educational needs. Some schools provide a family-based approach to education, encouraging parents to discuss any home-based life events that could impinge on the child's education, and involving parents actively in planning and reviewing the child's special educational needs. Finally, public

Peter L. Appleton is a consultant clinical psychologist and Head of Clinical Child Psychology, Brookside Family Consultation Clinic, Douglas House, 18d Trumpington Road, Cambridge CB2 2AH. He was, until recently, Head of a multi-agency primary care CAMH service in North Wales, and is participating in two primary care CAMH research studies funded by the Wales Office of Research \& Development in Health and Social Care. 
Box 1 Key characteristics of primary care health services (based on Starfield, 1992)

First contact access

Longitudinal care by a named practitioner

Access to comprehensive health and social care, including preventive care

Coordination of individual patient care

Family-centred provision of care

Local community orientation

sector schools, like general practices, have a local community orientation.

It can therefore be said that schools do provide primary care CAMHS, with certain possible advantages over GPs: children spend a lot of time in school, and teachers have specialised knowledge of children's normal development. However, GP and primary care health services have other possible advantages: knowledge of the child's developmental and medical history, and knowledge of the psychological and physical status of other family members.

However, for GPs and schools to be able to function as full primary care providers, access to specialist help for families is crucial. What is known about the interface between primary care and specialist CAMHS?

\section{The gap between primary care and specialist CAMHS}

In recent years, there has been explicit recognition in the UK of a significant divide between primary care and specialist CAMHS (see Box 2). If access to services is thought of in terms of filters, the majority of child psychiatric disorder occurring in the community is not detected in primary care, and when such disorder is detected, there is limited access to specialist help. The interface between specialist CAMHS and primary care has therefore become a central policy issue in CAMHS planning.

\section{Closing the gap: Tier 2}

The importance of the interface between primary care and specialist CAMHS has been emphasised in a number of recent national reports (Department of Health/Department for Education/Social Services
Box 2 Characteristics of the service 'gap' between primary care and specialist CAMHS (based on NHS/HAS, 1995)

Only the tip of the iceberg of child mental health problems and disorders are dealt with by specialist CAMHS

Specialist CAMHS are overstretched and are dealing with only the most severe and complex disorders

Long waiting times for specialist CAMHS are not helpful to patients, and deter primary care referrals

Primary care professionals would benefit from systematic training, support and consultation in identification and management of child mental health problems

Primary care professionals often know little about their local specialist CAMHS

Inspectorate, 1995; NHS/HAS, 1995; Audit Commission, 1999). In order to clarify the existing structure of services and make some headway in defining a future structure, a tiered model was introduced in 1995. Tier 1 refers to interventions (such as early identification, general advice for mild-moderate problems, and mental health promotion and prevention) provided by primary care and other front-line services. Tier 2 is regarded as the functional interface between Tier 1 and multidisciplinary specialist services, and may be defined as a level of service provided by specialist CAMH professionals working on their own who relate to others through a network rather than through a team (Audit Commission, 1999). Tier 2 represents the firstline of specialist services, and is clearly distinguished from the work of multi-disciplinary specialist teams who provide secondary level (Tier 3) and tertiary level (Tier 4) care for children with severe, complex and persistent disorders. The functions of Tier 2 are outlined in Box 3 and discussed in the following four sections.

It has been envisaged that Tier 2 functions could be carried out either by existing CAMH professionals (with specific time and remit), or by the creation of new outreach posts attached to Tier 3 teams (primary mental health workers). Between 1997 and 1999, the Audit Commission found that, on average, only $1 \%$ of specialist CAMH staff time was spent on providing Tier 2 services. No estimate of the number of new primary mental health worker Tier 2 posts created is available at the present time. 


\section{Training primary care colleagues}

Two patterns of training are evident in the literature. First, training may be targeted at primary care professionals who intend to continue providing an entirely generalist service. Bernard et al (1999) developed a teaching package for GP registrars designed to improve abilities in detection, assessment and management of mental health problems in adolescents. In a London study of $61 \mathrm{GP}$ registrars, there was evidence for positive changes in self-perceived competence, increased knowledge and increased recognition of adolescent psychiatric disorder.

Second, training may be aimed at primary care professionals who plan to devote a specific proportion of their time to non-specialist CAMH work. In a London study, health visitors and clinical medical officers were trained in parent counselling, parenting and child behaviour management (Davis, et al, 1997). These staff then provided a local clinical service under the supervision of Tier 2 child mental health specialists. In a controlled study, child and family outcome measures were promising, although the authors stress the need for replication (Davis \& Spurr, 1998).

Turning to educational settings, there is evidence that training teachers in effective classroom management can reduce rates of school-based aggressive behaviour (Hawkins et al, 1991).

In practice, during the early stages of comprehensive CAMHS development, it can be difficult to negotiate release of primary care colleagues for training and development work. Strategic planning agreement at primary care group trust and local authority chief executive level is essential before expecting primary care colleagues to make difficult choices between the many different demands on their time.

\section{Providing consultation to primary care}

Skills may also be disseminated via consultation. In the context of community-based mental health services, the term 'consultation' has a specific

\section{Box 3 Functions of Tier 2 CAMHS}

Providing training for Tier 1 colleagues

Consultation and liaison with Tier 1 colleagues

Direct specialist interventions for children and families whose needs cannot be met wholly at Tier 1

Gate-keeping access to Tiers 3 and 4 meaning, which derives originally from the work of Gerald Caplan (Caplan, 1970). Consultation may be defined as collaborative problem solving between a mental health specialist (the consultant) and one or more persons (the consultees) who are responsible for providing some form of psychological assistance to another (the client or patient). Consultation may take a range of forms, as outlined in Box 4 . There is a considerable literature on primary care consultation, in both health and educational settings, although some of it lacks systematic research (Medway \& Updyke, 1985; Meyers et al, 1993; Garralda, 1994).

Clearly, the purpose of consultation is to go beyond traditional teaching modes of communication, by engaging primary care colleagues in a sustained and interactive learning programme, usually involving a mutual commitment from both Tier 2 and Tier 1 professionals. Experienced consultants emphasise the considerable time investment involved in the early stages of setting up consultation links with schools or health care settings, as well as the importance of respecting status hierarchies in the 'host' organisation. For instance, consultation links with a school always require careful negotiation with the head teacher (and local education authority) before permission is granted for direct access to the front-line teaching staff. If a consultation is provided between agencies (e.g. psychiatrist to school), explicit work on stereotypes and differences of language may be of crucial significance in creating a working relation-

\section{Box 4 Types of CAMH consultation}

Informal ad hoc consultation about an individual patient, initiated by a primary care professional

'Client-centred' consultation about individual patients via regular meetings between a specialist and primary care professionals (individual or group)

'Consultee-centred' consultation about individual patients via regular meetings between a specialist and primary care professionals (individual or group)

Consultation about primary care CAMHS organisational change via regular meetings between a specialist and primary care professionals (individual or group)

Mediation (by a Tier 2 specialist) between primary care professionals regarding coordination of care for an individual patient 
ship. This may, of course, also be true for working within agencies.

Consultation about an individual child or family may result in a referral to Tier 2 when it is agreed that needs cannot be met at Tier 1 . Some referrals will be dealt with at Tier 2, whereas others may require referral for multi-disciplinary assessment and treatment.

\section{Tier 2 interventions}

Most interventions at Tier 2 involve active collaboration between Tier 2 and primary care. As we have seen, a Tier 2 service is usually provided in a context of training and consultation, with filtering and gatekeeping. Clinical referrals to Tier 2 provide an opportunity for a dialogue with Tier 1 about individual case management.

Clinical interventions provided for families seeking help constitute one category of service intervention. As CAMHS begin to take on a public health function, other categories of intervention will be adopted as evidence accrues for effectiveness. Offord et al (1998) outline three types of intervention, each contributing to a lowering of the burden of child psychiatric suffering in the population (see Box 5). In contrast to clinical interventions, which are provided for families seeking help, targeted interventions are aimed at children deemed to be at high risk of developing a disorder (e.g. children of drugmisusing parents), and universal interventions are aimed at all children in a geographical area or setting (e.g. a school). Targeted and universal interventions are provided without reference to individual helpseeking behaviour. A detailed analysis of trade-offs among each of these approaches is provided by Offord et al (1998).

\section{Tier 2 clinical interventions}

One example of an English Tier 2 clinical service (with universal components) is provided by Day et al (1998). In this service, on-site clinics are provided for children attending six general practices, covering a total population of 44000 people. In addition to clinical interventions provided by Tier 2 professionals, the service offers training and consultation to health visitors, school nurses and day nursery officers, and is also developing a range of schoolbased initiatives.

In one service in north Wales, a highly devolved Tier 2 clinical service (also with a universal component: see below) is provided in all primary schools and general practices in one locality with a total population of 14500 . Use of consultation and referral is managed within each separate school and general practice, enabling each primary care team (including its primary mental health worker) gradually to develop shared responsibility for child mental health need arising in its school roll or general practice list (Appleton \& HammondRowley, 2000).

\section{Tier 2 targeted interventions}

'Fast Track' provides an American example of a targeted Tier 2 /Tier 1 service aimed at reducing the population prevalence of antisocial behaviour (Conduct Problems Prevention Research Group (CPPRG), 1992). In a multi-site randomised controlled trial, children at school entry were screened for early signs of disruptive behaviour and poor peer relations. Theoretically based interventions were provided for parent-child behavioural management, peer socio-cognitive skills, academic skills and self-control. Initial outcome data from Fast Track show positive effects on children's social, emotional and academic skills, peer interactions and social status, conduct problems and use of special educational services (CPPRG, 1999a). In a recent metaanalysis of indicated interventions (i.e. targeted at children showing early problem signs), mean effect sizes of 0.51 and 0.53 were found for behavioural and cognitive-behavioural interventions respectively (Durlak \& Wells, 1998).

\section{Tier 2 universal interventions}

In one recent American study of a universal intervention (LIFT: Linking the Interests of Families and Teachers) aimed at reducing the prevalence of conduct problems, 32 classes in 12 primary schools (located in at-risk neighbourhoods) were randomly assigned to either a control or preventive intervention (Reid et al, 1999). Specially trained staff, working closely with teachers, provided parent training, classroom-based social and problem-solving skills training, a peer interaction intervention, and promotion of parent-teacher links. At 1-year follow-up, the intervention group showed significant decreases in aggressive behaviour. Importantly, the effects were seen across the whole range of pre-intervention severity. Other universal interventions have been designed to be delivered by primary care professionals, with training and support. For instance, the PATHS curriculum (Promoting Alternative THinking Strategies) is a classroom-based programme for promoting emotional and social competencies, and reducing aggression and behavioural problems in young school-age children. There are very promising classroom-based data from the USA supporting the impact of universal provision of PATHS (Greenberg \& Kusche, 1998; CPPRG, 1999b). 
In north Wales, the universal PATHS curriculum is being provided to whole classes of children in all primary schools in one geographically defined area in Flintshire. The PATHS intervention, combined with additional parallel consultation and clinical interventions, aims to reduce psychological morbidity in young school-age children in the defined area (Appleton \& Hammond-Rowley, 2000).

\section{Combining clinical, targeted and universal} interventions

When different types of intervention are combined (see Box 5), children requiring clinical interventions come to light during the provision of universal and targeted work. For instance, during universal PATHS curriculum provision in classrooms, some children disclose anxieties about home or school, anxieties which can be gently followed up with the child. In these circumstances, joint work by a Tier 2 professional and a teacher provides an opportunity for the teacher to develop a range of skills, including the involvement of parents in positive negotiation about their child's emotional needs across the home-school link.

Box 5 Categories of intervention aimed at lowering the burden of suffering from child psychiatric disorder (based on Offord et al, 1998)

Clinical: provided for a family with a child who is perceived to have a disorder and seeks help. The family is seen by a service at the relevant CAMHS tier.

Targeted: children or families are singled out for intervention because of high risk of developing a disorder. A child may be thought to be at high risk because of family or ecological circumstances (e.g. a parent misusing drugs or on low income), or child risk markers (e.g. aggressive behaviour in the first year of school). Previously known as secondary prevention.

Universal: all children in a geographical area or setting receive the intervention. An intervention may be aimed at all children in a high social deprivation neighbourhood or school, or at a larger geographic area. Previously known as primary prevention.

\section{Gate-keeping access to Tiers 3 and 4}

The fourth function of Tier 2 is to ensure that children with complex or severe disorders are referred to Tiers 3 or 4 for multi-disciplinary investigation and treatment. There will be a need to develop protocols to ensure that appropriate referrals are made, but it is also recognised that, in the presence of long waiting times for specialist work, Tier 2 services may have to 'hold' complex cases, providing a brief intervention and ensuring that inter-agency support resources are maximised for the family (see also Davis et al, 1997). There is the risk that if this process is not well managed, Tier 3 waiting times will be replicated at Tier 2, with consequent erosion of training, consultation and preventive intervention functions.

\section{Integration of functions of Tier 2}

In order to support primary care and other Tier 1 colleagues, Tier 2 provides a combination of training, consultation, collaborative interventions and gatekeeping. It is hoped that new Tier 2 services will begin to 'close the gap' between primary care and multi-disciplinary specialist services. However, this is a demanding set of responsibilities, and the future development of these functions will depend on a number of factors, to which I now turn.

\section{The future for Tier 2 support for primary care}

The notion of Tier 2 potentially broadens the scope of traditional, clinical CAMHS, by engaging with each of the characteristics and functions of primary care (see Box 1). In the future, at least eight factors deserve further attention (Box 6; see also Kramer \& Garralda, 2000).

\section{Organisation and development of Tier 2 functions}

In this journal, Gask \& Croft (2000) have drawn attention to the importance of identifying manageable steps in the development of primary-secondary mental health services. The authors highlight the 
Box 6 The future of the Tier 2 interface with primary care CAMHS: several issues

Organisation and development of Tier 2 functions

Access to CAMHS for children from ethnic minority groups

Training and supervision

Geographical planning

Children with severe and complex psychiatric disorder

Child protection

Children with a long-term physical illness or disability

Inter-agency collaboration

need for identifying the evidence base, for bringing together the key players at local level, for a local needs assessment, and for the involvement of service users. Earlier in this paper, the importance of strategic agreements at inter-agency chief executive level was emphasised. A case example of Tier 2 CAMHS development is provided in Box 7.

In general, CAMHS have found it impossible to begin substantive Tier 2 work without the creation of new primary child mental health specialist posts. Leadership and clinical supervision for colleagues in these posts then becomes crucial for planned organisation and development. To meet this requirement, some areas have invested in a consultant-level Tier 2 CAMH specialist post, sometimes working in equal partnership with a local authority (or voluntary agency) senior manager (ideally with extensive specialist educational or children's social care experience).

\section{Access to CAMHS for children from ethnic minority groups}

Equal access to CAMHS for children from ethnic minority groups is essential (Cooper et al, 1998). During the needs assessment stage of Tier 2 service, there is an early opportunity to seek guidance from ethnic minority community leaders on appropriate service structures and processes, including membership of stakeholder groups.

\section{Training and supervision}

Existing literature rightly emphasises the training needs of Tier 1 . However, there is an equally
Box 7 Case example: development of Flintshire (north Wales) Tier 2 service (based on Appleton \& Hammond-Rowley, 2000)

Posts established (NHS: Tier 2 consultant clinical psychologist, Tier $2 / 3$ clinical psychology link post, one full-time primary child mental health specialist; local education authority: dedicated sessional input from educational psychology)

Geographical area defined (14 500 total population; urban)

Further funding obtained (Barnardo's: one full-time primary child mental health specialist; NHS: dedicated sessional input from general practice adult psychological therapist)

Multi-agency stakeholder committee formed, together with extensive local networking

$R$ \& D funding obtained (Wales Office of R \& D for Health and Social Care)

Needs assessment conducted by new service staff and research assistant (structured interviews with general population sample of parents, and local professionals working with families)

Service objectives agreed with stakeholders Interventions (based on needs assessment and literature) and $R$ \& D model agreed with stakeholders

Mode of service delivery (named attachmentliaison to all general practices and primary schools) agreed with stakeholders

Service and research launched with local media support

important need for accredited continuing professional development (CPD) training for CAMH professionals taking on Tier 2 duties. Working in community settings requires new skills. Supervision is also important, and in small services may be difficult to access. Creative inter-agency linkages, and sharing of supervision resources across geographical areas may address this problem during early stages of service development.

\section{Geographical planning}

There has been little discussion in the literature on the appropriate nature and size of geographical unit for Tier 2 services. At least two issues arise. First, whether or not socially disadvantaged 
areas should be 'targeted'. Benefits of this approach include increased access for a high-risk population, and increased support for primary care colleagues working in high-need areas. A disadvantage is the stigma that may accrue to an area when new services are seen to target it. One option is to choose an area that includes a wide spectrum of level of need (Appleton \& HammondRowley, 2000).

A second issue is the size of the geographical area chosen for provision. Three approaches seem to be evident in the literature. The first approach is to provide services to a large area (total population exceeding 40 000), beginning with a subset of Tier 1 services that are either 'organisationally ready' or show particularly high need (see Day et al, 1998). The second is to choose a small area (total population 10 000-20 000) and provide comprehensive Tier 2 services to all inter-agency primary care facilities (Appleton \& Hammond-Rowley, 2000). A third method is to begin with one or two general practices (Coverley et al, 1995). Choice of approach will depend on the purposes of the planned service and the resources available.

\section{Children with severe and complex psychiatric disorder}

As Box 1 indicates, longitudinal and coordinating responsibility for children and families with severe and complex problems resides with primary care. Schools are responsible for managing children with severe difficulties in the classroom. Primary care health services are responsible for continuing to care for children after Tiers 3 or 4 have completed clinical interventions. In emphasising the early identification role of Tier 1 , the current tiered model does not fully address the role of primary care in long-term care and education of children with complex difficulties. More often than not, both a parent and a child in such families may be experiencing psychiatric disorder. Currently, new Tier 2 services are asked to help with complex cases, sometimes before and sometimes after Tier 3 or 4 involvement, but inevitably the intensive nature of this clinical and consultancy work will erode the wider functions of Tier 2. Strategic inter-agency plans will need to identify specific resources for multi-tier training and support for work with children with severe and complex disorder, concentrating on the frontline demands on Tier 1 staff. Gask \& Croft (2000) draw attention to the potential of shared care plans in GP management of complex cases. In CAMHS, there is also a need to focus shared care plans on the partnership between the school and family.

\section{Child protection}

Schools and primary care health services are at the front line in identification of risk of child abuse and neglect (Department of Health, Home Office \& Department for Education and Employment, 1999: paras 3.10-3.14, 3.28-3.38). Often, emotional and behavioural difficulties are the first clues that a child may be at risk of, or experiencing, abuse or neglect. It is important, therefore, that new Tier 2 services recognise the implications of possible increased early recognition of risk of abuse and neglect, as primary care professionals improve in their detection of CAMH problems.

\section{Children with a long-term physical illness or disability}

Most children with a chronic illness cope well but as a group they are at higher risk of psychiatric disorder than physically well children, especially if there is neurological involvement. It is important that the mental health needs of these children are met in community and school settings, where social inclusion can be promoted. A link is important between inter-agency child disability services and Tier 2 CAMHS, to ensure that mental health needs can be addressed in the community.

\section{Inter-agency collaboration}

The two ground-breaking CAMH strategy documents published in 1995 (Department of Health/Home Office/Department for Education and Employment, 1995; NHS/HAS, 1995) were explicitly multi-agency in their orientation. Since the election of a new UK Government in 1997, that theme has continued, with, for instance, joint circulars requiring agencies to submit jointly agreed CAMH strategies. However, considering Box 1, if the primary care tier of CAMHS is to develop in a 'seamless' fashion, the notions of first contact access, longitudinal care, comprehensive access, individual coordination of care and education, and family and community-centred service will need to be approached from an inter-agency perspective. Tier 2 services are in a strong position to promote such an approach if they themselves are funded and managed on an inter-agency basis.

\section{References}

\footnotetext{
Appleton, P. L. \& Hammond-Rowley, S. (2000) Addressing the population burden of child and adolescent mental health problems: a primary care model. Child Psychology and Psychiatry Review, 5, 9-16.
} 
Audit Commission (1999) Children in Mind: Child and Adolescent Mental Health Services. London: Audit Commission.

Bernard, P., Garralda, E., Hughes, T. \& Tylee, A. (1999) Evaluation of a teaching package in adolescent psychiatry for general practitioner registrars. Education for General Practitioners, 10, 21-28.

Bowman, F. M. \& Garralda, M. E. (1993) Psychiatric morbidity among children who are frequent attenders in general practice. British Journal of General Practice, 43, 6-9.

Caplan, G. (1970) The Theory and Practice of Mental Health Consultation. London: Tavistock.

Conduct Problems Prevention Research Group (CPPRG) (1992) A developmental and clinical model for the prevention of conduct disorder: the Fast Track Program. Development and Psychopathology, 4, 509-527.

- (1999a) Initial impact of the Fast Track prevention trial for conduct problems: the high-risk sample. Journal of Consulting and Clinical Psychology, 67, 631-647.

- (1999b) Initial impact of the Fast Track prevention trial for conduct problems: classroom effects. Journal of Consulting and Clinical Psychology, 67, 648-657.

Cooper, H., Smaje, C. \& Arber, S. (1998) Use of health services by children and young people according to ethnicity and social class: secondary analysis of a national survey. British Medical Journal, 317, 1047-1051.

Coverley, C. T., Garralda, M. E., Bowman, F. (1995) Psychiatric intervention in primary care for mothers whose schoolchildren have psychiatric disorder. British Journal of General Practice, 45, 235-237.

Davis, H. \& Spurr, P. (1998) Parent counselling: an evaluation of a community child mental health service. Journal of Child Psychology and Psychiatry, 39, 365-376.

- - Cox, A., et al (1997) A description and evaluation of a community child mental health service. Clinical Child Psychology and Psychiatry, 2, 221-238.

*Day, C., Davis, H. \& Hind, R. (1998) The development of a community child and family mental health service. Child: Care, Health and Development, 24, 487-500.

Department of Education and Science (1978) Special Education Needs: Report of the Commitee of Enquiry into the Education of Handicapped Children and Young People. London: HMSO.

Department of Health/Department for Education/Social Services Inspectorate (1995) A Handbook on Child and Adolescent Mental Health. London: Department of Health.

Department of Health/Home Office/Department for Education and Employment (1999) Working Together to Safeguard Children: A Guide to Inter-Agency Working to Safeguard and Promote the Welfare of Children. London: Stationery Office.

Durlak, J. A. \& Wells, A. M. (1998) Evaluation of indicated preventive intervention (secondary prevention) mental health programs for children and adolescents. American Journal of Community Psychology, 26, 775-802.

Garralda, M. E. (1994) Primary care psychiatry. In Child and Adolescent Psychiatry: Modern Approaches (eds M. Rutter, E. Taylor \& L. Hersov), pp. 1055-1070. Oxford: Blackwell.

Gask, L. \& Croft, J. (2000) Methods of working with primary care. Advances in Psychiatric Treatment (in press).

Greenberg, M. T. \& Kusche, C. (1998) Blueprints for Violence Prevention, Book Ten: Promoting Alternative Thinking Strategies (PATHS). Boulder, Colorado: Institute of Behavioral Science, University of Colorado.

Hawkins, J., von Cleve, E. \& Catalano, R. (1991) Reducing early childhood aggression: results of a primary prevention program. Journal of the American Academy of Child and Adolescent Psychiatry, 30, 208-217.

*Kramer, T. \& Garralda, M. E. (2000) Child and adolescent mental health problems in primary care. Advances in Psychiatric Treatment, 6, 287-294.

Medway, F. J. \& Updyke, J. F. (1985) Meta-analysis of consultation outcome studies. American Journal of Community Psychology, 13, 489-505.

Meyers, J., Brent, D., Faherty, E., et al (1993) Caplan's contributions to the practice of psychology in schools. In Consultation in Community, School, and Organizational Practice:
Gerald Caplan's Contributions to Professional Psychology (ed. W. P. Erchul), pp. 99-122. London: Taylor and Francis.

*National Health Service/Health Advisory Service (1995) Child and Adolescent Mental Health Services: Together We Stand. The Commissioning Role and Management of Child and Adolescent Mental Health Services. London: HMSO.

${ }^{*}$ Offord, D. R., Kraemer, H. C., Kazdin, A. E., et al (1998) Lowering the burden of suffering from child psychiatric disorder: trade-offs among clinical, targeted, and universal interventions. Journal of the American Academy of Child and Adolescent Psychiatry, 37, 686-694.

Reid, J. B., Eddy, J. M., Fetrow, A., et al (1999) Description and immediate impacts of a preventive intervention for conduct problems. American Journal of Community Psychology, 27, 483-517.

Rutter, M. (1989) Isle of Wight revisited: twenty-five years of child psychiatric epidemiology. Journal of the American Academy of Child and Adolescent Psychiatry, 28 633-653.

Starfield, B. (1992) Primary Care: Concept, Evaluation, and Policy. Oxford: Oxford University Press.

* indicates articles of particular interest

\section{Multiple choice questions}

1. Primary care implies:

a first contact service access

b public health responsibilities

c coordination of care

d local education authority services

e schools.

2. CAMHS Tier 1 includes:

a primary care NHS

b tertiary care NHS

c all front-line social care services

d parents

e schools.

3. CAMHS Tier 2 may provide:

a support to GPs

b specialist multi-disciplinary treatment for complex problems

c consultation to schools

d specialist uni-disciplinary interventions

e universal and targeted interventions.

4. Targeted interventions:

a are aimed at children at high risk of psychiatric disorder

$\mathrm{b}$ are provided for families seeking help with specific problems

c are provided for all children in a specific neighbourhood

d might be provided for all children of mothers with clinical depression

e might be provided for all children showing early signs of depression in adolescence. 
5. Starting a Tier 2 service requires:

a inter-agency strategic planning

b comprehensive geographical coverage

c involvement of Tier 1 local colleagues and families in service design

d clinical supervision for primary child mental health specialists

e explicit service objectives.
MCQ answers

$\begin{array}{lllll}1 & 2 & 3 & 4 & 5\end{array}$

a $\mathrm{T}$ a $\mathrm{T}$ a $\mathrm{T}$ a $\mathrm{T}$ a $\mathrm{T}$

b $\begin{array}{lllllll} & \text { b } F & \text { b } F & \text { b F } & \text { b F }\end{array}$

c $T$ c $T$ c $T$ c $\quad F \quad$ c $T$

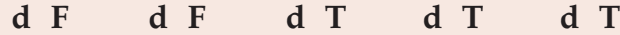

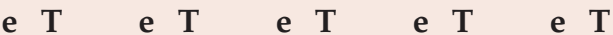

\section{NEW FROM GASKELL}

\section{The Mental Health Needs of Looked After Children}

Joanna Richardson \& Carol Joughin

Young people in the care system have a much higher rate of mental health problems than those in the general population. Failure to acknowledge and treat these problems may cause difficulties for these children ranging from placement breakdowns to more serious mental health problems in later life. This book is valuable to anyone who has contact with young people in care in particular social workers and foster carers.

Developed with a number of professionals, the book aims to help those caring for and working with these vulnerable young people to:

- identify and understand the mental health problems and social issues that may exist for these children;

- be made aware of the importance of recognising mental health problems and therefore the importance of prevention;

- improve understanding of current developments in child and adolescent mental health services, specifically joint working between health and social services.

August 2000, paperback, £14.00, ISBN 190124248 X

\section{Finding the Evidence: A Gateway to the Literature in Child and Adolescent Mental Health}

Carol Joughin \& Mike Shaw

This resource provides clinicians and trainees with easy access to research evidence and current thinking in child and adolescent mental health. 'Experts' from each area have assisted in compiling this resource, which will be updated on an annual basis. The authors have searched for robust secondary research, key reports and clinical practice guidelines on a wide range of topic areas as well as including cutting edge and classic papers, reviews and books. A section that addresses various approaches to searching for information, search strategies and critical appraisal tools is also included.

We envisage Finding the Evidence: A Gateway to the Literature in Child and Adolescent Mental Health as a 'living document' evolving to address the growing demand for knowledge and plan to exploit the new opportunities provided by information technology.

July 2000, paperback, £12.00, ISBN 1901242501

Book Sales, The Royal College of Psychiatrists, 17 Belgrave Square, London SW1X 8PG. Telephone +44 (0)20 72352351 ext. 146; Fax +44 (0)20 72451231 